\title{
Correction to: Early impairment of coronary microvascular perfusion capacity in rats on a high fat diet
}

Judith van Haare' ${ }^{1}$, M. Eline Kooi², Hans Vink', Mark J. Post', Jurgen W. G. E. van Teeffelen '1, Jos Slenter², Chantal Munts ${ }^{1}$, Hanneke Cobelens ${ }^{1}$, Gustav J. Strijkers ${ }^{4}$, Dennis Koehn ${ }^{5}$ and Marc van Bilsen ${ }^{1,3^{*}}$

\section{Correction to: Cardiovasc Diabetol (2015) 14:150} https://doi.org/10.1186/s12933-015-0312-2 Following publication of the original article [1], the authors regret errors in Fig. $3 \mathrm{~b}-\mathrm{d}$. In these figures, the images of the representative Akt and phospho-Akt (pAkt) signals should be replaced with the appropriate images. The representative images shown here are correct. The changes do not affect the scientific conclusion and significance of the article. 
b

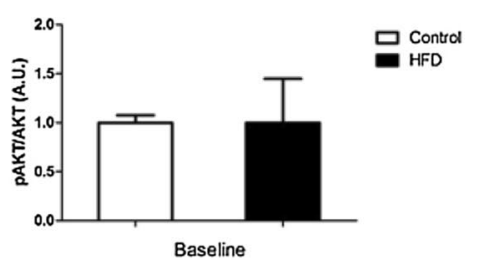

C

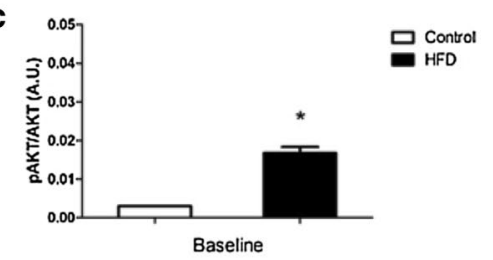

d

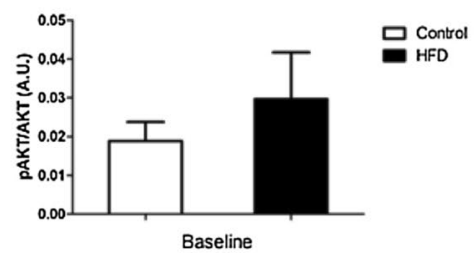

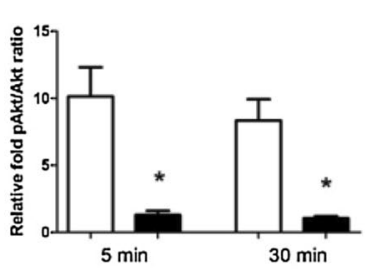
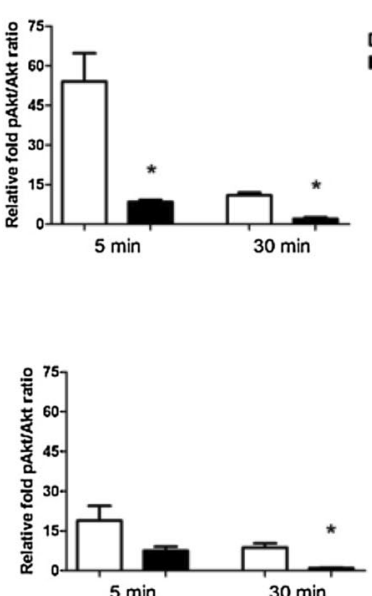
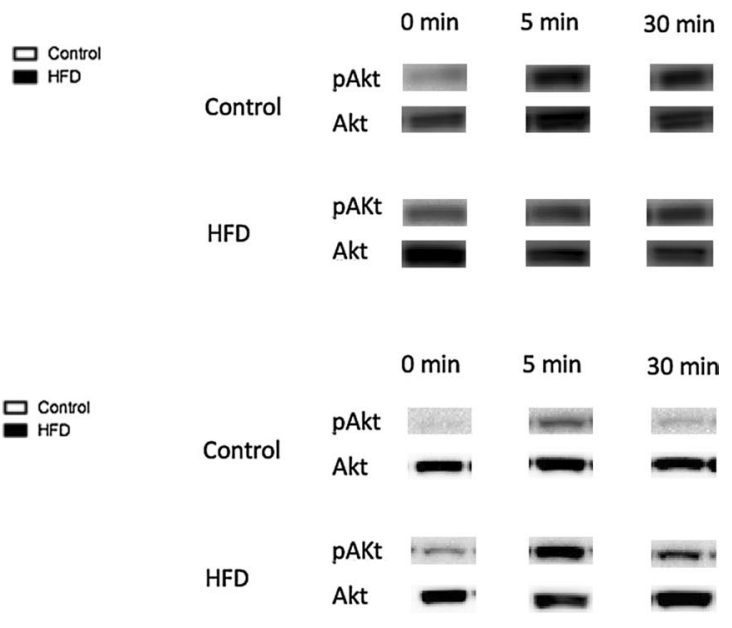

$\square$ Control

-

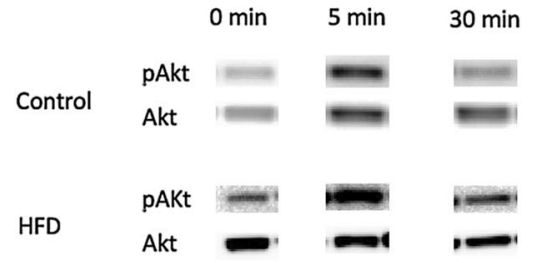

\section{Author details}

${ }^{1}$ Department of Physiology, CARIM School for Cardiovascular Diseases, Maastricht University, P.O. Box 616, 6200 MD Maastricht, The Netherlands. ${ }^{2}$ Department of Radiology, CARIM School for Cardiovascular Diseases, Maastricht University, P.O. Box 616, 6200 MD Maastricht, The Netherlands. ${ }^{3}$ Department of Cardiology, CARIM School for Cardiovascular Diseases, Maastricht University, P.O. Box 616, 6200 MD Maastricht, The Netherlands. ${ }^{4}$ Biomedical Engineering and Physics, Academic Medical Center, P.O. Box 22700, 1100 DE Amsterdam, The Netherlands. ${ }^{5}$ Pie Medical Imaging, P.O. Box 1132, 6201 BC Maastricht, The Netherlands.

Received: 6 February 2021 Accepted: 6 February 2021

Published online: 22 February 2021

\section{Reference}

1. van Haare J, Kooi ME, Vink H, Post MJ, van Teeffelen JW, Slenter J, Munts C, Cobelens H, Strijkers GJ, Koehn D, van Bilsen M. Early impairment of coronary microvascular perfusion capacity in rats on a high fat diet. Cardiovasc Diabetol. 2015;14:150.

\section{Publisher's Note}

Springer Nature remains neutral with regard to jurisdictional claims in published maps and institutional affiliations. 